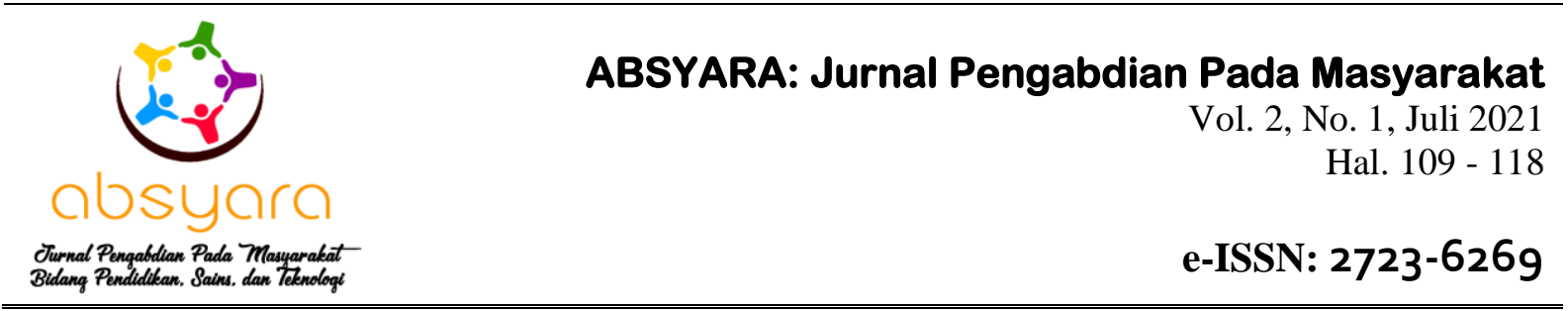

\title{
Pengenalan Object Theatre pada Remaja Bremi Lombok Timur
}

\author{
Riyana Rizki Yuliatin*1, Puspita Dewi ${ }^{2}$, Baiq Desi Dwi Arianti ${ }^{3}$, Hary Murcahyanto ${ }^{4}$ \\ riyanarizki.y@ gmail.com*1 \\ 1,3,4 Pendidikan Sendratasik, Fakultas Bahasa, Seni, dan Humaniora, Universitas Hamzanwadi \\ ${ }^{2}$ Ilmu Komunikasi, Fakultas Teknik, Universitas Bumigora
}

Received: 1 Juni 2021

Accepted: 8 Juli $2021 \quad$ Online Published: 31 Juli 2021

DOI: 10.29408/ab.v2i1.3585 URL: http://dx.doi.org/10.29408/ab.v2i1.3585

\begin{abstract}
Abstrak: Teater merupakan salah satu bidang seni pertunjukan yang menampilkan perilaku manusia di atas panggung. Kehidupan manusia diwakilkan melalui cerita, dialog, dan laku para tokoh. Salah satu gaya dalam seni teater adalah object theatre. Teater objek melibatkan manipulasi objek untuk memberi kehidupan pada objek yang digunakan, sehingga ada permainan timbal balik antara pemain dan objek. Object theatre sendiri masih tergolong baru di Indonesia, sehingga kegiatan ini bertujuan untuk mengenalkan object theatre pada masyarakat. Sasaran kegiaatan ini adalah Remaja Bermi, Kelurahan Pancor yang berusia 17-20 tahun. Hal ini dikarenakan remaja bisa menjadi media penyebarluasan informasi yang lebih cepat ke geneasi selanjutnya. Kegiatan dilakukan selama 4 bulan dengan jumlah peserta sebanyak 14 orang. Metode pelatihan yang digunakan pada kegiatan ini adalah workshop, pendampingan latihan, dan pertunjukan di balai Desa Pengadangan yang menjadi lokasi gempa pada tahun 2018. Hasil kegiatan menunjukan bahwa peserta pelatihan mampu mementaskan pertunjukan object theatre dan mampu mengendalikan diri selama pertunjukan dengan tidak stealing the show.
\end{abstract}

Kata Kunci: Object Theatre; Pelatihan Teater; Pengendalian Diri; Workshop;

\begin{abstract}
The theatre is one of the performing arts fields that display human behaviour on stage. Human life is represented through stories, dialogues, and the behaviour of the characters. One of the styles in theatre art is object theatre. Object theatre involves manipulating objects to give life to the objects used so that there is a reciprocal play between the player and the object. Object theatre itself is still relatively new in Indonesia, aiming to introduce object theatre to the public. The target of this activity is Bermi Youth, Pancor Village aged 17-20 years. Teenagers can become a faster medium for disseminating information to the next generation. The activity was held for four months with a total of 14 participants. The training methods used in this activity are workshops, training assistance, and performances at the Pengadangan Village hall, which was the earthquake's location in 2018. The activity results showed that the trainees were able to stage object theatre performances and control themselves during the show by not stealing the show.
\end{abstract}

Keyword: Object Theatre; Selft Control; Theater Performance Training; Workshop; 
Yuliatin, R. R., Dewi, P., Arianti, B. D. D., Murcahyanto, H. (2021). Pengenalan Object Theatre pada remaja Bremi Lombok Timur. ABSYARA: Jurnal Pengabdian Pada Masyarakat, 2(1), 109-118. doi:10.29408/ab.v2i1.3585

\section{PENDAHULUAN}

Bagi dunia luar, object theatre bukan barang baru. Akan tetapi bentuk teater ini belum begitu populer di Indonesia. Meskipun demikian, telah bermunculan pelaku-pelaku object theatre ini. Sebut saja Papermoon Puppet Theatre dan Flying Ballon Puppet Theatre. Kedua kelompok teater ini merupakan kelompok yang memainkan teater dengan media boneka. Mereka menjadikan boneka sebagai subjek di panggung atau menjadi aktor, sehingga keduanya masuk dalam peta pelaku object theatre. Pertunjukan Papermoon Puppet Theatre dilakukan dengan memanipulasi kehadiran objek dan kisah disajikan tanpa kata (Mayangsari \& Abdillah, 2019). Di awal perjalannya, Papermoon Puppet Theatre mengombinasikan teknik berbeda untuk membentuk "aktor" mereka, seperti menggunakan sampah atau benda-benda yang ditemukan atau dengan menggunakan boneka serupa Muppet dalam ukuran aslinya (Lis, 2018)

Object theatre berbeda dengan teater pada umumnya. Dalam teater modern, object atau benda menjadi properti yang melengkapi dan menambah keestetikan pertunjukan (Garner Jr, 1998), sedangkan dalam object theatre, objek atau benda itu menjadi pusat perhatian penonton. Frank Proschan mendefinisikan object theatre sebagai gambaran material dari manusia, binatang, atau jiwa yang diciptakan untuk ditampilkan (Bell, 1997). Dengan kata lain, object theatre menampilkan objek lain sebagai sosok dalam panggung. Ia menggantikan kehadiran manusia. Sementara itu manusia berada di balik "hidup"nya aktor-aktor yang diciptakan tadi. Meski terlihat mudah, object theatre memiliki tingkat kesulitan yang tergolong tinggi. Seorang aktor (manusia) yang menggerakkan sebuah objek harus mampu mengendalikan dirinya (tubuh) agar ia sebagai sosok bayangan tidak stealing the show. Pertunjukkan tetaplah milik objek yang ia mainkan, bukan milik manusia yang mengerakkan objek tersebut.

Dalam satu abad, object theatre telah berubah dari pendekatan teater yang bersifat teknis dan kerajinan menjadi bentuk teater dengan kepekaan yang fokus pada wujud (Astles, 2010). Pada mulanya, menurut Astles, boneka atau wayang sangat penting dalam objek theatre telah bergeser pada bentuk animasi materi, objek, bayangan, dan bentuk lain yang dianggap fana (Astles, 2010). Kajian lain tentang object theatre dilakukan oleh Muneroni dan Leeuwen. Dari kajian ini dapat dilihat bahwa pertunjukan Roswitha dari drama latin Gandersheim Sapientia yang jarang muncul dalam pertunjukan panggung profesional justru menjadi sangat kekinian dan menarik melalui pementasan object theatre (Muneroni \& Leeuwen, 2019). Berangkat dari penelitian Muneroni dan Leeuwen, kegiatan ini ingin memperkenalkan obejct theatre pada remaja. Dalam riset yang dilakukan oleh Yuliatin dan Satrya HD disebutkan bahwa peta teater Lombok masih didominasi oleh teater modern (Yuliatin \& Satrya, 2019), sehingga penting untuk mengenalkan beragam bentuk teater termasuk object theatre yang masuk dalam peta teater kontemporer.

Kegiatan pengenalan ini dilakukan di Bermi Kelurahan Pancor, kampung yang terletak di dekat Universitas Hamzanwadi, yaitu sekitar 3-4 kilometer. Kegiatan ini melibatkan peserta sebanyak 14 orang dengan rentasng usia 17-20 tahun. Bermi memiliki remaja yang aktif dalam berkesenian. Hal ini terbukti dengan munculnya kelompok kesenian remaja yang aktif berkegiatan. Dipilihnya remaja yang aktif dalam kegiatan kesenian dikarenakan mereka mampu menjadi penyambung pengetahuan baru kepada generasi selanjutnya. Dalam kasus ini, mereka akan mementaskan hasil latihan di hadapan masyarakat Desa Pengadangan yang 
menjadi korban gempa. Seperti yang diketahui, bencana alam memiliki kemungkinan destruktif tidak hanya pada bangunan, tetapi juga pada mental manusia. Bencana alam seperti gempa bisa saja menimbulkan stres atau trauma yang jika tidak dikelola dengan baik dapat "membunuh" dan seni memiliki kekuatan penyembuhnya sendiri (Ide, 2009) Bagi dunia luar, object theatre bukan barang baru. Akan tetapi bentuk teater ini belum begitu populer di Indonesia. Meskipun demikian, telah bermunculan pelaku-pelaku object theatre ini. Sebut saja Papermoon Puppet Theatre dan Flying Ballon Puppet Theatre. Kedua kelompok teater ini merupakan kelompok yang memainkan teater dengan media boneka. Mereka menjadikan boneka sebagai subjek di panggung atau menjadi aktor, sehingga keduanya masuk dalam peta pelaku object theatre. Pertunjukan Papermoon Puppet Theatre dilakukan dengan memanipulasi kehadiran objek dan kisah disajikan tanpa kata (Mayangsari \& Abdillah, 2019). Di awal perjalannya, Papermoon Puppet Theatre mengombinasikan teknik berbeda untuk membentuk "aktor" mereka, seperti menggunakan sampah atau benda-benda yang ditemukan atau dengan menggunakan boneka serupa Muppet dalam ukuran aslinya (Lis, 2018)

Object theatre berbeda dengan teater pada umumnya. Dalam teater modern, object atau benda menjadi properti yang melengkapi dan menambah keestetikan pertunjukan (Garner Jr, 1998), sedangkan dalam object theatre, objek atau benda itu menjadi pusat perhatian penonton. Frank Proschan mendefinisikan object theatre sebagai gambaran material dari manusia, binatang, atau jiwa yang diciptakan untuk ditampilkan (Bell, 1997). Dengan kata lain, object theatre menampilkan objek lain sebagai sosok dalam panggung. Ia menggantikan kehadiran manusia. Sementara itu manusia berada di balik "hidup"nya aktor-aktor yang diciptakan tadi. Meski terlihat mudah, object theatre memiliki tingkat kesulitan yang tergolong tinggi. Seorang aktor (manusia) yang menggerakkan sebuah objek harus mampu mengendalikan dirinya (tubuh) agar ia sebagai sosok bayangan tidak stealing the show. Pertunjukkan tetaplah milik objek yang ia mainkan, bukan milik manusia yang mengerakkan objek tersebut.

Dalam satu abad, object theatre telah berubah dari pendekatan teater yang bersifat teknis dan kerajinan menjadi bentuk teater dengan kepekaan yang fokus pada wujud (Astles, 2010). Pada mulanya, menurut Astles, boneka atau wayang sangat penting dalam objek theatre telah bergeser pada bentuk animasi materi, objek, bayangan, dan bentuk lain yang dianggap fana (Astles, 2010). Kajian lain tentang object theatre dilakukan oleh Muneroni dan Leeuwen. Dari kajian ini dapat dilihat bahwa pertunjukan Roswitha dari drama latin Gandersheim Sapientia yang jarang muncul dalam pertunjukan panggung profesional justru menjadi sangat kekinian dan menarik melalui pementasan object theatre (Muneroni \& Leeuwen, 2019). Berangkat dari penelitian Muneroni dan Leeuwen, kegiatan ini ingin memperkenalkan obejct theatre pada remaja. Dalam riset yang dilakukan oleh Yuliatin dan Satrya HD disebutkan bahwa peta teater Lombok masih didominasi oleh teater modern (Yuliatin \& Satrya, 2019), sehingga penting untuk mengenalkan beragam bentuk teater termasuk object theatre yang masuk dalam peta teater kontemporer.

Kegiatan pengenalan ini dilakukan di Bermi Kelurahan Pancor, kampung yang terletak di dekat Universitas Hamzanwadi, yaitu sekitar 3-4 kilometer. Kegiatan ini melibatkan peserta sebanyak 14 orang dengan rentasng usia 17-20 tahun. Bermi memiliki remaja yang aktif dalam berkesenian. Hal ini terbukti dengan munculnya kelompok kesenian remaja yang aktif berkegiatan. Dipilihnya remaja yang aktif dalam kegiatan kesenian dikarenakan mereka 
mampu menjadi penyambung pengetahuan baru kepada generasi selanjutnya. Dalam kasus ini, mereka akan mementaskan hasil latihan di hadapan masyarakat Desa Pengadangan yang menjadi korban gempa. Seperti yang diketahui, bencana alam memiliki kemungkinan destruktif tidak hanya pada bangunan, tetapi juga pada mental manusia. Bencana alam seperti gempa bisa saja menimbulkan stres atau trauma yang jika tidak dikelola dengan baik dapat "membunuh" dan seni memiliki kekuatan penyembuhnya sendiri (Ide, 2009).

\section{METODE PELAKSANAAN}

\section{Waktu dan Lokasi}

Kegiatan ini berlangsung selama 4 bulan, dimulai dari bulan Agustus hingga Desember 2018. Workshop pengenalan dilakukan dalam 2 hari sedangkan pembinaan dan pendampingan untuk persiapan pentas dilakukan sekali dalam seminggu. Alokasi waktu dalam setiap pertemuannya yaitu 90 menit. Kegiatan dilakukan pada hari Sabtu. Dimulai pukul 16.00 sampai dengan 17.30. Dipilih hari Sabtu sore agar proses ini tidak mengganggu kegiatan belajar peserta. Akan tetapi, setiap kegiatan tetap dalam pemantauan.

Kegiatan dilakukan di dua tempat, yaitu Panggung Putih Universitas Hamzanwadi yang berlamatkan di Jl. Cut Nyak Dien No.85, Pancor, Selong, Kabupaten Lombok Timur dan Balai Desa Pengadangan, Kabupaten Lombok Timur. Kantor Desa Pengadangan dipilih karena dua alasan. Pertama, pada momen itu gempa di Lombok baru saja terjadi dan Desa Pengadangan menjadi satu dari sekian wilayah terdampak di daerah Lombok Timur. Kedua, gempa menimbulkan ketakutan sehingga warga tidak banyak begitu nyaman berada di dalam ruangan sehingga dipilihlah lokasi pertunjukan di balai desa sebab memiliki panggung kecil terbuka. Lokasi dipilih karena menjadi lokasi terdampak gempa tetapi tidak terlalu terekspose sehingga tidak banyak yang mengetahui (Yuliatin, 2020)..

\section{Prosedur pelaksanaan}

Kegiatan dilakukan dalam bentuk pembinaan remaja Bremi, Kelurahan Pancor. Pembinaan berupa workshop, diskusi, hingga penggarapan pertunjukan, atau praktek object theatre. Workshop dipilih agar memudahkan peserta memahami konsep dasar tentang object theatre. Bahan-bahan yang dibutuhkan selama workhsop berupa sebuah laptop dan 2 buah botol mineral ukuran besar dan sedang. Sedangkan bahan yang dibutuhkan selama latihan dan penggarapan pertunjukan berupa koran bekas, pilox putih untuk mewarnai koran bekas, kain/selendang, kain putih sepanjang 5 meter, alat musik berupa gitar dan biola. Bahan untuk pertunjukan berupa satu set lampu pertunjukan dan sound system. Prosedur kegiatan dimulai dengan melakukan workshop selama 2 hari di Panggung Putih Universitas Hamzanwadi. Pada minggu selanjutnya dimulai penggarapan konsep pertunjukan. Setelah konsep matang, peserta mulai menyiapkan bahan dan memulai latihan. Kegiatan ditutup dengan pementasan peserta di balai desa.

Ketercapaian tujuan dilihat dari kemampuan peserta mementaskan pertunjukan object theatre di hadapan warga terdampak gempa. Selain itu juga para peserta dapat mementaskan object theatre tanpa stealing the show. Dalam mementaskan object theatre, aktor (yang dalam hal ini adalah peserta) tidak boleh menjadi pusat perhatian, seperti pada teater konvensional. Objek yang dimainkan harus menjadi yang utama. Sehingga akan menjadi tantangan bagi 
aktor untuk membiarkan dirinya bersembunyi di balik objek yang dimainkan dan tidak muncul secara dominan dalam pertunjukan atau lazim disebut dengan stealing the show

\section{HASIL DAN PEMBAHASAN}

HASIL

Pemberian materi dilakukan dengan pretest. Pretest ini dilakukan dengan memberikan beberapa pertanyaan secara verbal pada para peserta. Pertanyaan-pertanyaan tersebut berkaitan dengan object theatre. Hal ini dilakukan untuk melihat dan mengukur pengetahuan peserta tentang object theatre. Misalnya dengan menanyakan (1) pernahkah mereka mendengar istilah ini sebelumnya, dan (2) pernahkah mereka memiliki pengalaman memainkan object sebelumnya. Dari pertanyaan-pertanyaan tersebut para peserta meunjukkan respons yang baik. Mereka tertarik dengan materi yang akan mereka pelajari, sebab bagi mereka object theatre adalah hal baru. Selain itu object theatre belum pernah mereka dengar sebelumnya. Pelaksaan kegiatan ini dilakukan dalam 3 tahap. Kegiatan dimulai dengan pemberian materi tentang object theatre, kemudian dilanjutkan dengan pembagian peran dan latihan, terakhir dengan mengadakan pementasan object theatre di tempat yang telah disepakati.

Pada kegaitan pertama diikuti oleh sejumlah 14 remaja Bermi, Kelurahan Pancor. Pada pertemuan yang berisi materi ini dapat dilihat tingginya antusias peserta untuk mengikuti kegiatan ini. Berdasarkan pertanyaan yang diberikan dapat diketahui tidak satupun peserta yang mengetahui apa itu object theatre, bahkan tidak ada satupun mereka yang pernah mendengar istilah ini.

Pada pengenalan pertama, peserta diajak untuk menonton video pertunjukkan object theatre. Dengan memperlihatkan secara visual suatu pertunjukkan dapat memberikan referensi awal yang lebih nyata pada peserta dan bisa menghilangkan bosan dan lelah akibat tingginya level kesulitan materi (Gultom, 2010). Setelah mereka mendapat gambaran apa itu object theatre, barulah masuk pada materi object theatre.

Dalam proses penyampaian materi, dilakukan dengan urutan sebagai berikut. Pertama dimuali dengan penjelasan singkat mengenai definisi teater. Materi kemudian dilanjutkan dengan materi tentang metode dan teknik memainkan object theatre. Untuk memudahkan peserta menerima penjelasan teoretis digunakan media botol bekas dengan dua ukuran, yaitu besar dan kecil.

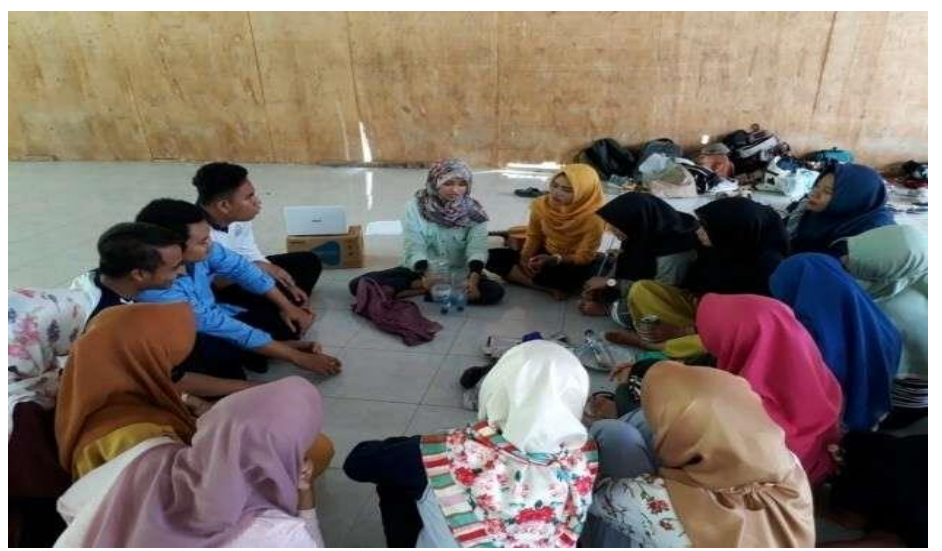

Gambar 1. Peserta diperkenalkan bentuk object theatre dengan menggunakan media botol mineral bekas ukuran besar dan sedang. 
Melalui dua botol mineral bekas seperti yang ada pada gambar tersebut, peserta menjadi lebih mudah memahami konsep object theatre merupakan storytelling with the object (Ryoppy et al., 2018).

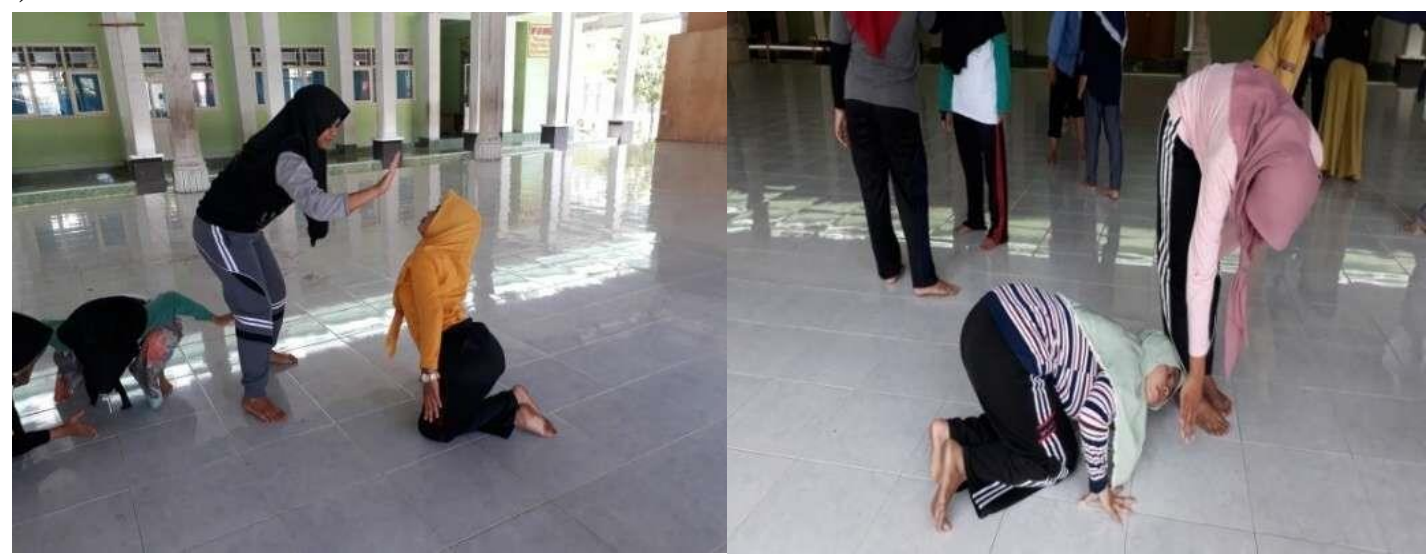

Gambar 2. Peserta sedang melakukan olah tubuh

Kedua gambar tersebut memperlihatkan peserta melakukan olah tubuh dengan teknik fluid sculpture. Teknik ini berfokus pada pencapaian kelenturan tubuh aktor dan membiarkan tubuh menyatu dengan sekitarnya. Kehadiran aktor dan pergerakannya di area permainan menunjukkan relasi antara tubuh aktor dan tempat ia berada (Abe, 2016). Dalam teknik ini, peserta dipasangkan. Satu orang akan menjadi pemandu yang akan menggerakkan individu lainnya, atau yang menjadi boneka. Sementara yang menjadi boneka akan mengikuti kemana tangan pemandunya akan bergerak. Dengan menggunakan teknik ini peserta dapat melenturkan tubuh dan mengatur "kelenturan" tubuh pasangannya. Olah tubuh ini tidak hanya bertujuan untuk melenturkan tubuh aktor, tetapi juga menyiapkan aktor untuk siap menjadi pengendali yang sekaligus di momen yang bersamaan masuk ke dalam objek yang dikendalikannya.

Pada pertemuan selanjutnya, peserta diperkenalkan pada berbagai jenis objek yang bisa menjadi subjek di panggung. Pada dasarnya segala hal di dunia ini bisa menjadi objek dalam object theatre. Mulai dari barang bekas seperti botol hingga selendang, bahkan daun yang kita kira hanya menjadi sampah di halaman rumah. Setelah itu peserta mulai mengidentifikasi barang-barang yang bisa mereka mainkan nantinya. Setelah melakukan diskusi, mereka pun memutuskan untuk menggunakan koran bekas. Peserta pun bersepakat untuk pertemuan berikutnya membawa koran dan kertas bekas, lakban, dan pilok dan bersepakat untuk mulai membentuk subjek panggung seperti yang dapat dilihat pada gambar berikut. 


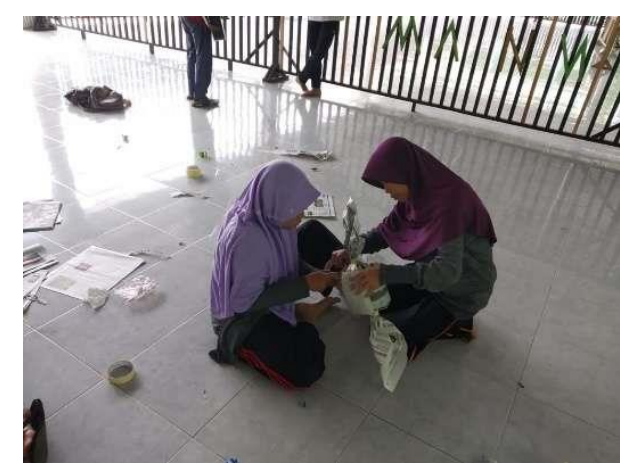

Gambar 4. Peserta membuat objek panggung dengan koran bekas

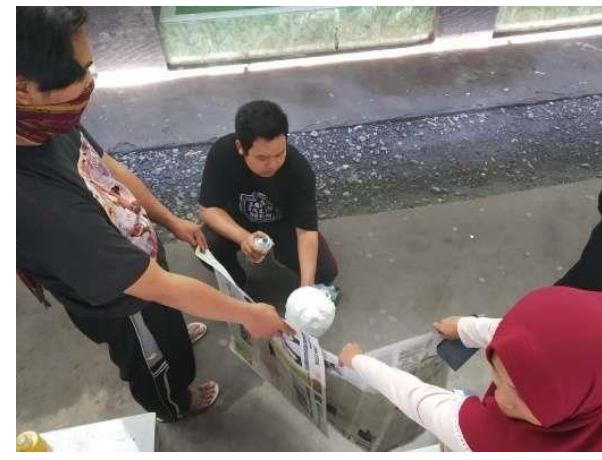

Gambar 5. Peserta mewarnai objek

Foto-foto tersebut memperlihatkan agenda peserta workshop yang membuat objek mereka sendiri. Mulai dari membentuk tubuh, mewarnai objek dengan pilok, hingga memberikan atribut sebagai salah satu identitas objek itu sendiri. Dalam kegiatan ini, telah disepakati bahwa satu objek akan dimainkan oleh dua orang. Satu objek yang dimainkan oleh dua orang tentu memiliki kesulitannya sendiri. Masing-masing orang harus menyingkronkan tubuhnya dengan tubuh pasangannya agar objek yang dimainkan bergerak dengan natural seperti yang terlihat pada gambar berikut.

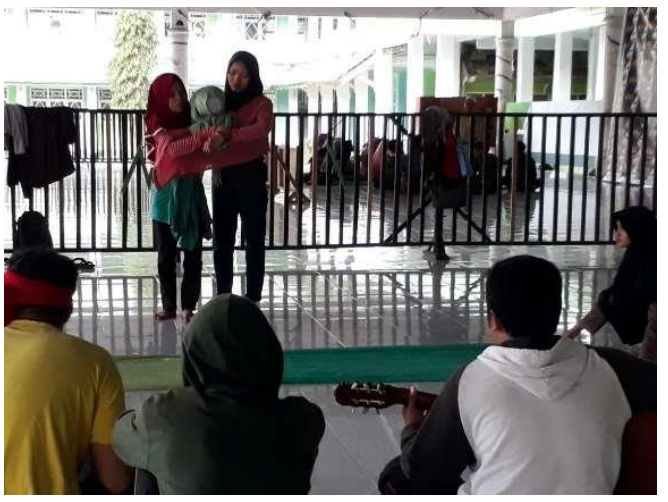

Gambar 6. Peserta mulai latihan dengan iringan musik pengiring

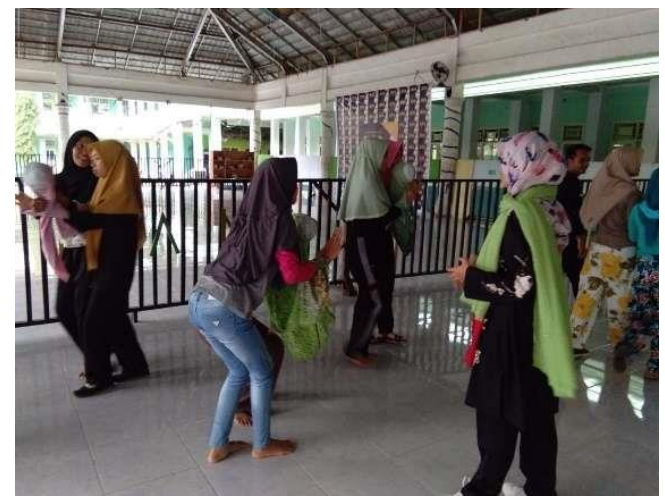

Gambar 7. pemantauan proses latihan mingguan untuk menyatukan diri dengan objek yang dimainkan

Pada mulanya, latihan dilakukan sekali dalam seminggu. Memasuki bulan kedua latihan, intensitas latihan dinaikkan menajdi 2 dua kali dalam seminggu. Tetap pada sore hari agar tidak mengganggu waktu belajar peserta. Mendekati waktu perunjukan, latihan kembali ditingkatkan menajdi 3 kali dalam seminggu untuk semakin membiasakan dan memperkuat ikatan peserta dengan objek yang dimainkannya.

Dalam proses latihan, peserta harus membangun koordinasi tubuh dengan pasangannya. Gerak mereka harus seirama dan halus agar tidak menarik perhatian penonton sebab mereka bukanlah tokoh melainkan sosok yang menggerakkan objek. Sedangkan objek yang dimainkan 
adalah sosok utama yang harus menjadi pusat perhatian penonton. Selain itu, melalui latihan pertunjukan ini peserta diajarkan untuk menekan ego agar tidak stealing the show.

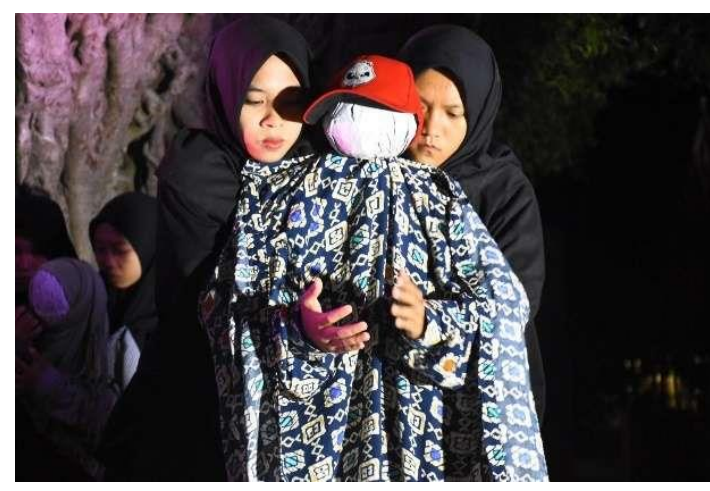

Gambar 8. Peserta memainkan objek

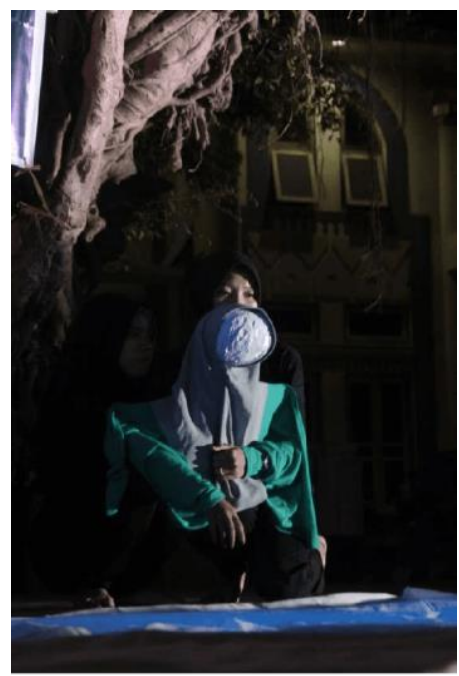

Gambar 10. Peserta memainkan objek

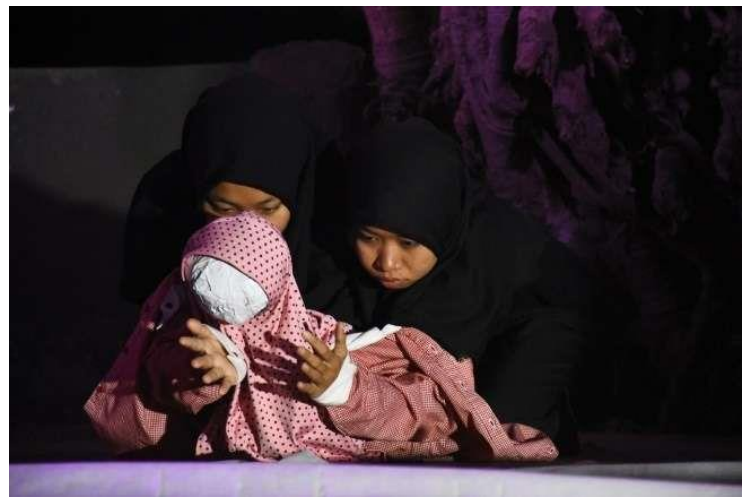

Gambar 9. Peserta memainkan objek

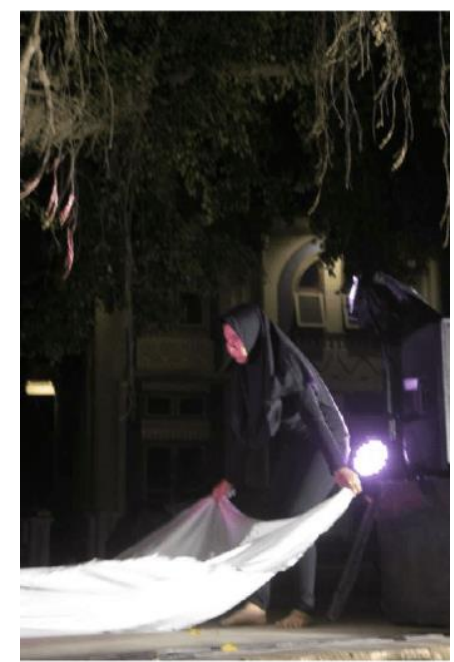

Gambar 11. Peserta memainkan objek

Foto-foto tersebut memperlihatkan peserta yang sedang mementaskan pertunjukkan teater objek di balai Desa Pengadangan. Terlihat perubahan dan perkembangan yang signifikan dari para peserta. pada sesi-sesi latihan sering kali mereka melakukan stealing the show dengan bergerak secara berlebihan, tersenyum. Tetapi pada pertunjukkan tidak sedikitpun mereka melakukan hal-hal yang menjadi kesalahan saat latihan.

\section{PEMBAHASAN}

Metode berteater ini meski tidak berfokus pada manusia sebagai individu, tetapi membutuhkan penguasaan terhadap tubuh. Tubuh harus benar-benar bisa dikendalikan agar tidak menjadi perhatian penonton dan pada akhirnya stealing the show. Pemain teater objek pada dasarnya harus bisa mengendalikan tubuhnya agar tidak lebih menonjol dari objek yang dimainkan. Meski demikian tidak berarti tubuh dibiarkan begitu saja. Tubuh juga harus siap mengendalikan objek. Meski ia diberikan nama sebagai sebuah objek, tetapi dalam pertunjukkan ia tetaplah sebagai subjek yang menjadi center point 
penonton. Ia tetap harus memiliki nyawa, seperti bergerak dengan keinginannya sendiri. Itulah mengapa dibutuhkan tubuh yang siap dari seorang pupheteer. Maka dari itu, sebelum melakukan teater ini tubuh harus disiapkan terlebih dahulu.

Kesuksesan peserta melakukan pertunjukan ini menunjukkan kemampuan pengendalian diri mereka yang baik. Kesalahan dalam latihan adalah suatu kewajaran. Peserta sedang dalam proses menemukan titik penyatuan diri dengan objek yang dimainkannya. Melalui object theatre ini, pengendalian diri sangat harus bisa dimiliki oleh peserta. Jika tidak mereka dapat membangun gerakan-gerakan yang tidak seharusnya dan bisa mengalihkan perhatian penonton dari objek yang dimaikan ke diri peserta itu sendiri. Pengendalian diri dalam kegiatan ini mulai dibangun sejak dilakukannya olah tubuh. Teknik olah tubuh fluid sclupture membantu peserta merasakan sendiri tubuh mereka melemah dan dikuasai pihak lain. Mereka membiarkan tubuh mereka menyatu dengan hal lain yang menggerakkannya. Dalam pertunjukan object theatre sendiri, pengendalian diri harus dibangun secara perlahan melalui latihan rutin. Pengendalian diri ini tidak hanya bermanfaat untuk di atas panggung, tetapi juga dalam keseharian peserta

\section{SIMPULAN}

Object theatre menjadi salah satu bentuk pertunjukkan teater yang jarang diketahui oleh peserta. Object theatre memiliki kesulitan dan kemudahannya tersendiri. Kesulitan terletak pada menekan diri sendiri agar tidak stealing the show. Kemudahannya muncul dari minimnya menghapalkan naskah yang biasanya menjadi kesulitan bagi para aktor pemula. Saat turun ke lapangan untuk mementaskan pertunjukkan object theater, peserta melakukan tugasnya dengan sangat baik dan yang terpending adalah tidak stealing the show. Melalui kegiatan pengenalan ini, peserta mendapatkan pengalaman baru berteater dengan memainkan objek sebagai tokoh utama. Sehingga bisa dikatakan bahwa tujuan kegiatan dapat terealisasi dengan mampunya peserta memahami tentang object theatre dan mementaskannya tanpa stealing the show.

\section{PERNYATAAN PENULIS}

Artikel ini merupakan hasil program pengabdian kepada masyarakat pada saat gempa Lombok 2018 di Lombok Timur. Dengan ini penulis menyatakan bahwa tulisan ini belum pernah dipublikasikan di jurnal lain.

\section{DAFTAR PUSTAKA}

Abe, M. (2016). Membaca Makna Ruang dan Peristiwa pada Pertunjukan Saidja Karya Papermoon Puppet Theatre dan Het Volksoperahuis. Jurnal Kajian Seni, 2(2), 116-131.

Astles, C. (2010). Puppetry Training for Contemporary Live Theatre. Theatre, Dance and Performance Training, 1(1), 22-35.

Garner Jr, S. B. (1998). Staging "Things": Realismandthe Theatrical Object in Shepard's Theatre. Contemporary Theatre Review, 8(3), 55-66. http://www.tandfonline.com/loi/gctr20

Gultom, J. J. (2010). Pemanfaatan Media dalam Proses Belajar Mengajar. Jurnal Bahasl, 
Yuliatin, R. R., Dewi, P., Arianti, B. D. D., Murcahyanto, H. (2021). Pengenalan Object Theatre pada remaja Bremi Lombok Timur. ABSYARA: Jurnal Pengabdian Pada Masyarakat, 2(1), 109-118. doi:10.29408/ab.v2i1.3585

20(03), 1-8. https://jurnal.unimed.ac.id/2012/index.php/bahas/article/view/2618

Ide, P. (2009). Creative Healing (1st ed.). PT Elex Media Komputindo.

Lis, M. (2018). The History of Loss and the Loss of History: Papermoon Puppet Theatre Examines the Legacies of the 1965 Violence in Indonesia. In The Indonesian Genocide of 1965 (pp. 253-268).

Mayangsari, H., \& Abdillah, A. (2019). Bentuk Pertunjukan Papermoon Puppet Theatre dalam Cerita "Secangkit Kopi dari Playa." APRON Jurnal Pemikiran Seni Pertunjukan, 1(13), 1-14. https://jurnalmahasiswa.unesa.ac.id/index.php/apron/article/view/28709/26284

Muneroni, S., \& Leeuwen, M. Van. (2019). Rediscovering Roswitha's Sapientia with Object Theatre. Contemporary Theatre Review, 29(2), 152-165. https://www.tandfonline.com/doi/full/10.1080/10486801.2019.1591387

Ryoppy, M., Konstatinovs, P., Poulsen, S. B., \& Ylirisku, S. (2018). Object Theatre in Field Study. Innovation Conference 2018, 286-292.

Yuliatin, R. R. (2020). Playback Theatre sebagai Metode Pelepasan Ketegangan Pasca Gempa Lombok pada Anak-Anak. ABDI POPULIKA, 1(1), 1-11.

Yuliatin, R. R., \& Satrya, D. (2019). Logat, Volume 6, No 2, November 2019. LOGAT: Jurnal Bahasa Indonesia Dan Pembelajaran, 6(2), 137-150. 